\title{
Within- and between-generation effects of temperature on early fecundity of Drosophila melanogaster
}

\author{
RAYMOND B. HUEY*, TAMEKIA WAKEFIELD†, WAYNE D. CRILL $\ddagger \&$ \\ GEORGE W. GILCHRIST \\ Department of Zoology NJ-15, University of Washington, Seattle, WA 98195, †Department of Biology, Rhodes College, \\ Memphis, TN 38112 and $\ddagger$ Department of Zoology, University of Texas, Austin, TX 78712, U.S.A.
}

\begin{abstract}
We used a repeated-measures, four-factor experimental design to determine how the fecundity of Drosophila melanogaster during the first 5 days of adult life was influenced by paternal, maternal, developmental and laying temperature, with two different temperature levels $\left(18^{\circ} \mathrm{C} \mathrm{vs.} 25^{\circ} \mathrm{C}\right)$ per factor. Laying temperature had by far the largest effect on fecundity and accounted for 79 per cent of the variance in overall fecundity: flies laying at $25^{\circ} \mathrm{C}$ began laying eggs about a day earlier and had much higher daily fecundities than did those laying at $18^{\circ} \mathrm{C}$. Developmental temperature had no significant effect either on overall fecundity or on the pattern of daily egg production. Dam temperature had a slight effect on the pattern of daily egg production, but not on overall fecundity. In contrast, sire temperature slightly influenced both overall fecundity and the pattern of daily egg production. Our results demonstrate that early fecundity is extraordinarily sensitive to laying temperature $\left(360\right.$ per cent increase if laying at $25^{\circ} \mathrm{C}$ vs. at $\left.18^{\circ} \mathrm{C}\right)$, but is relatively well buffered against developmental and cross-generational effects (maximum effect only 7 per cent, for sire temperature).
\end{abstract}

Keywords: Drosophila melanogaster, fecundity, reaction norm, parental effects, temperature.

\section{Introduction}

Fecundity is a major determinate of female fitness (Roff, 1992; Stearns, 1992). A given female's fecundity can be influenced by her genetics (Robertson, 1957), body size (Robertson, 1957), age (David, 1988) and also by her mate or by male effects (Markow \& Ankney, 1984; Hoffmann \& Harshman, 1985; Partridge et al., 1986; Pitnick, 1991). Fecundity is also strongly influenced by environmental factors such as crowding and temperature (Robertson \& Sang, 1944; David et al., 1983). Fecundity in Drosophila, for example, may depend not only on the temperature a female experiences as adult (Dobzhansky, 1935; David et al., 1983), but also on the temperature she experienced during development: thus females raised at extremely low or high temperatures are typically less fecund than are females raised at intermediate temperatures (Lints \& Lints, 1971; Cohet \& David, 1978; McKenzie, 1978).

*Correspondence.
Prior studies (above) have demonstrated that fecundity is very sensitive to laying temperature, or to developmental temperature; but no previous study had simultaneously measured whether fecundity was sensitive to laying, developmental and parental temperature regimes. Many life-history traits of organisms are affected by maternal (Riska et al., 1985; Kirkpatrick \& Lande, 1989; Daan et al., 1990; Mousseau \& Dingle, 1991) and even paternal (Giesel, 1988) environments. Significant cross-generational effects have important implications (Mousseau \& Dingle, 1991) not only for the design of experiments to estimate heritability (Riska et al., 1989), but also for attempts to predict short-term evolutionary responses to selection (Kirkpatrick \& Lande, 1989).

Here we investigate the between- and within-generation effects of temperature on fecundity of Drosophila melanogaster early in life. Specifically, we developed a factorial experiment that independently manipulated sire, dam, developmental and laying temperatures. Our experimental design enabled us not only to assay the sensitivity of fecundity to the various factors, but also to rank the magnitude of those sensitivities. 
The two temperature levels $\left(18^{\circ} \mathrm{C}\right.$ and $\left.25^{\circ} \mathrm{C}\right)$ we used for each factor (i.e. paternal, maternal, developmental and laying temperature) are routinely experienced by developing $D$. melanogaster in nature (McKenzie, 1975; Parsons, 1978; Jones et al., 1987; Izquierdo, 1991). Thus our experimental results should be ecologically relevant. We focused on fecundity over the first 5 days of adult life: (i) because Drosophila are typically short-lived as adults in nature (mean adult life expectancy $=1.3-6.2$ days; Rosewell \& Shorrocks, 1987), and (ii) because a recent sensitivity analysis verifies that minor shifts in fecundity of $D$. melanogaster early in life have much greater impact on fitness than do equivalent shifts in late fecundity (Stearns \& Kawecki, 1995).

This project was conducted in parallel with investigations of the effects of parental and developmental temperatures on several other traits (male territoriality: Zamudio et al., 1994; heat resistance, thermal dependence of running speed, body mass, wing size, abdominal melanization and egg size: W. Crill, R. B. Huey and G. W. Gilchrist, unpublished data). All these traits are influenced by developmental temperature, and some are influenced by parental temperature as well.

\section{Materials and methods}

\section{Stocks of flies}

Drosophila melanogaster used in this experiment originated from a large stock (1000 isofemale lines, courtesy of L. Harshman and M. Turelli) that had been collected in Escalon, CA, in May 1991 and maintained at the University of California, Davis, at room temperature (about $22^{\circ} \mathrm{C}$ ) 13:11 L:D cycle. We received a sample (about 1000 flies) in April 1992 and began rearing them (cornmeal, molasses, yeast, agar, tegosept) at low and controlled density in population cages of 2000-3000 individuals with discrete 2-week generations at $22^{\circ} \mathrm{C}$ on a $12: 12 \mathrm{~L}: \mathrm{D}$ cycle. We ran the present experiments in July through August 1992; thus, the flies had been in captivity for about 14 months and should have been reasonably adapted to the laboratory environment (Service \& Rose, 1985; Kohane \& Parsons, 1986).

\section{Experimental overview}

We manipulated two levels each of the sire's temperature, dam's temperature, offspring developmental temperatures and offspring laying temperature, and then replicated the experiment (thus 32 treatment groups). We raised parental flies at either moderate $\left(25^{\circ} \mathrm{C}\right)$ or low $\left(18^{\circ} \mathrm{C}\right)$ temperatures and crossed them at an intermediate temperature in the four possible sex-by-developmental temperature combinations $\left(\right.$ dam $_{18} \times$ sire $_{18}, \quad$ dam $_{18} \times$ sire $_{25}, \quad$ dam $_{25} \times$ sire $_{18}$, dam $_{25} \times$ sire $\left._{25}\right)$. The resulting eggs were then collected and raised at either moderate or low temperature $\left(25^{\circ} \mathrm{C}\right.$ or $\left.18^{\circ} \mathrm{C}\right)$. Within a few hours of eclosion, emerging virgins were isolated and then placed in trios (one female with two males, all with the same thermal history; see below) at either $18^{\circ} \mathrm{C}$ or $25^{\circ} \mathrm{C}$. Beginning 1 day later and then for the next 4 days, we tossed over each trio into a fresh vial and counted the eggs produced during the previous day.

We scored fecundity for all treatment groups within a given replicate over the same 5-day period: this ensured that treatment groups during laying would be exposed to common environmental, nutrient and handling conditions. However, because development time is highly sensitive to temperature (David et al., 1983), such synchrony during laying could be achieved only by staggering the times of egg collection (based on Ashburner, 1989; supplemented from pilot experiments) for the different temperature treatments. For example, eggs for the treatment in which sire, dam and offspring were all to be raised at $16^{\circ} \mathrm{C}$ were collected (from the same stock) well before those for the treatment in which sire, dam and offspring were to be raised at $25^{\circ} \mathrm{C}$. (Eggs were collected at intermediate times for treatments with mixed temperatures (e.g. sire at $18^{\circ} \mathrm{C}$, dam at $25^{\circ} \mathrm{C}$ ).) However, because we anticipated that development times over two generations would drift from those expected (Ashburner, 1989), we actually set up sets of eggs for each treatment group over 3 consecutive days and then used flies from different groups that became adults synchronously (see below).

\section{Details of treatment groups}

Parental flies were collected as eggs (from the founding stock at $22^{\circ} \mathrm{C}$ ) over two consecutive 5 -h periods and transferred to 40 vials $(50-70$ eggs/vial $)$ then moved to either $25^{\circ} \mathrm{C}$ or $18^{\circ} \mathrm{C}$. This egg collection procedure minimized the time that the eggs remained at $22^{\circ} \mathrm{C}$, thereby reducing any embryonic acclimation prior to transfer to their respective developmental temperatures. These flies, which formed the parental generation, were collected as virgins from these vials by tossing out the earliest eclosing flies, and subsequently collecting the flies that eclosed over the next $8 \mathrm{~h}$ (thus only flies from near the mean eclosion period are included in the analysis). Male and female virgins were aged in separate vials (20-30 per vial) at their respective developmental temperatures until ready for 
mating. To adjust for different 'physiological' ages of parents raised at different temperatures (Long et al., 1980; Taylor, 1981; David, 1988), we mated flies that had been raised at $18^{\circ} \mathrm{C}$ at 5 days of age but those that had been raised at $25^{\circ} \mathrm{C}$ at 3 days of age (these ages were scaled to the time from egg to adult at these two temperatures). Crosses of dams and sires were made at an intermediate temperature $\left(22^{\circ} \mathrm{C}\right)$, so that all parents experienced a minor temperature change prior to reproducing.

Eggs for the offspring generation were collected from the four parental crosses over two consecutive 5 -h periods at $22^{\circ} \mathrm{C}$. These eggs were then moved into vials (50-70 eggs per vial) and transferred to either $25^{\circ} \mathrm{C}$ or $18^{\circ} \mathrm{C}$ for development, resulting in eight different groups of offspring. (The short collection periods minimized the exposure of eggs at $22^{\circ} \mathrm{C}$, thereby reducing any embryonic acclimation, and also ensured that all eggs experienced an early temperature shift.) As mentioned above, we had staggered set-up times so that all treatments would eclose on the same day.

\section{Fecundity}

Within $8 \mathrm{~h}$ of eclosing, a virgin female was grouped with two virgin males that had the same temperature history. (Because both males and females had a common temperature history, we hoped to magnify any potential effects of parental or developmental temperature on fecundity (see Discussion).) We initially set up 15 trios per group. Then, once a day for 5 days, we tossed over the flies into fresh vials and counted the number of eggs in the previous vial. Two of us counted eggs each day, and we randomized the groups we scored on a given day. If a male escaped or died, we replaced him with a virgin male with the same age and thermal history. If a female escaped or died, she was not replaced and was excluded from the analysis. At the end of the period, we closely examined each trio and discarded four trios that accidently contained two females.

\section{Statistical analysis}

We excluded certain females from analysis: four trios that contained two females; females $(N=57)$ that died or that escaped during transfer, or that never laid any eggs; or females $(N=17)$ that began but stopped laying (these were assumed to be damaged). The resulting statistical analyses were based on 393 females, which produced a total of 76164 eggs.

Egg counts were approximately normally distributed within the two laying temperatures and so were not transformed. We used a multivariate analysis of variance with repeated measures (SPSS for Windows, release 6.0 ) to estimate the between-subjects effects (Table 1), which assess the effect of different temperature treatments on overall fecundity during the entire laying period, as well as the within-subjects effects (Table 2), which assess effects of the treatments on the daily patterns of egg laying. The replicate showed no significant interaction with any main effect. Moreover, the replicate mean square was smaller than the residual mean square (Table 1). Therefore, the effect of the

Table 1 Between-subjects effects on overall fecundity during the first 5 days of life of Drosophila melanogaster

\begin{tabular}{lrrrrr}
\hline Source of variation & d.f. & Sum of squares & Mean square & \multicolumn{1}{c}{$F$} & $P$ value \\
\hline Replicate & 1 & 127 & 127 & 0.22 & 0.637 \\
Sire & 1 & 3188 & 3188 & 5.62 & 0.018 \\
Dam & 1 & 142 & 142 & 0.25 & 0.617 \\
Development & 1 & 1341 & 1341 & 2.36 & 0.125 \\
Lay & 1 & 880831 & 880831 & 1552.05 & 0.000 \\
Development $\times$ lay & 1 & 2 & 2 & 0 & 0.951 \\
Development $\times$ dam & 1 & 51 & 51 & 0.09 & 0.764 \\
Development $\times$ sire & 1 & 2113 & 2113 & 3.72 & 0.054 \\
Lay $\times$ dam & 1 & 1391 & 1391 & 2.45 & 0.118 \\
Lay $\times$ sire & 1 & 2437 & 2437 & 4.29 & 0.039 \\
Dam $\times$ sire & 1 & 1303 & 1303 & 2.30 & 0.131 \\
Residual & 381 & 216228 & 568 & & \\
\hline
\end{tabular}

Lay temperature clearly had the dominant effect on fecundity, but sire's temperature was also significant. The analysis is a repeated-measures design (see Materials and methods) using unique sums of squares. Within-subjects effects are presented in Table 2. 
Table 2 Tests of within-subjects effects on patterns of daily egg production during the first 5 days of life of Drosophila melanogaster

\begin{tabular}{|c|c|c|c|c|}
\hline Source of variation & d.f. & Pillai's trace & Exact $F$ & $P$ value \\
\hline Day & $4 ; 378$ & 0.9379 & 1426.49 & 0.000 \\
\hline Replicate & $4 ; 378$ & 0.0044 & 0.41 & 0.798 \\
\hline Sire & $4 ; 378$ & 0.0247 & 2.39 & 0.050 \\
\hline Dam & $4 ; 378$ & 0.0300 & 2.92 & 0.021 \\
\hline Development & $4 ; 378$ & 0.0170 & 1.64 & 0.165 \\
\hline Lay & $4 ; 378$ & 0.8 & 398.50 & 0.000 \\
\hline Develc & $4 ; 378$ & 0.0047 & 0.44 & 0.779 \\
\hline Development $\times$ dam & $4 ; 378$ & 0.0116 & 1.10 & 0.354 \\
\hline Development $\times$ sire & $4 ; 378$ & 0.0267 & 2.59 & 0.036 \\
\hline Lay $\times$ dam & $4 ; 378$ & 0.0274 & 2.66 & 0.032 \\
\hline Lay $\times$ sire & $4 ; 378$ & 0.0322 & 3.14 & 0.015 \\
\hline Dam $\times$ sire & $4 ; 378$ & 0.0195 & 1.88 & 0.113 \\
\hline
\end{tabular}

Between-subjects effects are presented in Table 1. replicate was not combined with the residuals, as this would have inflated the significance levels of the various factors.

To quantify the actual numerical impact of different effects (i.e. magnitude of dam effect vs. that of sire) on the total number of eggs laid over 5 days, we computed the difference between the least-squares means (total eggs) for each effect (e.g. mean fecundity for dam effect at $18^{\circ} \mathrm{C}$ and at $25^{\circ} \mathrm{C}$ ). The difference between these two means (Fig. 2) serves as an index of the sensitivity of fecundity to that effect relative to other effects.

\section{Results \\ Laying temperature}

The temperature at which a female laid her eggs had the largest and most dramatic effect on overall egg production during the first 5 days of adult life (Fig. 1,

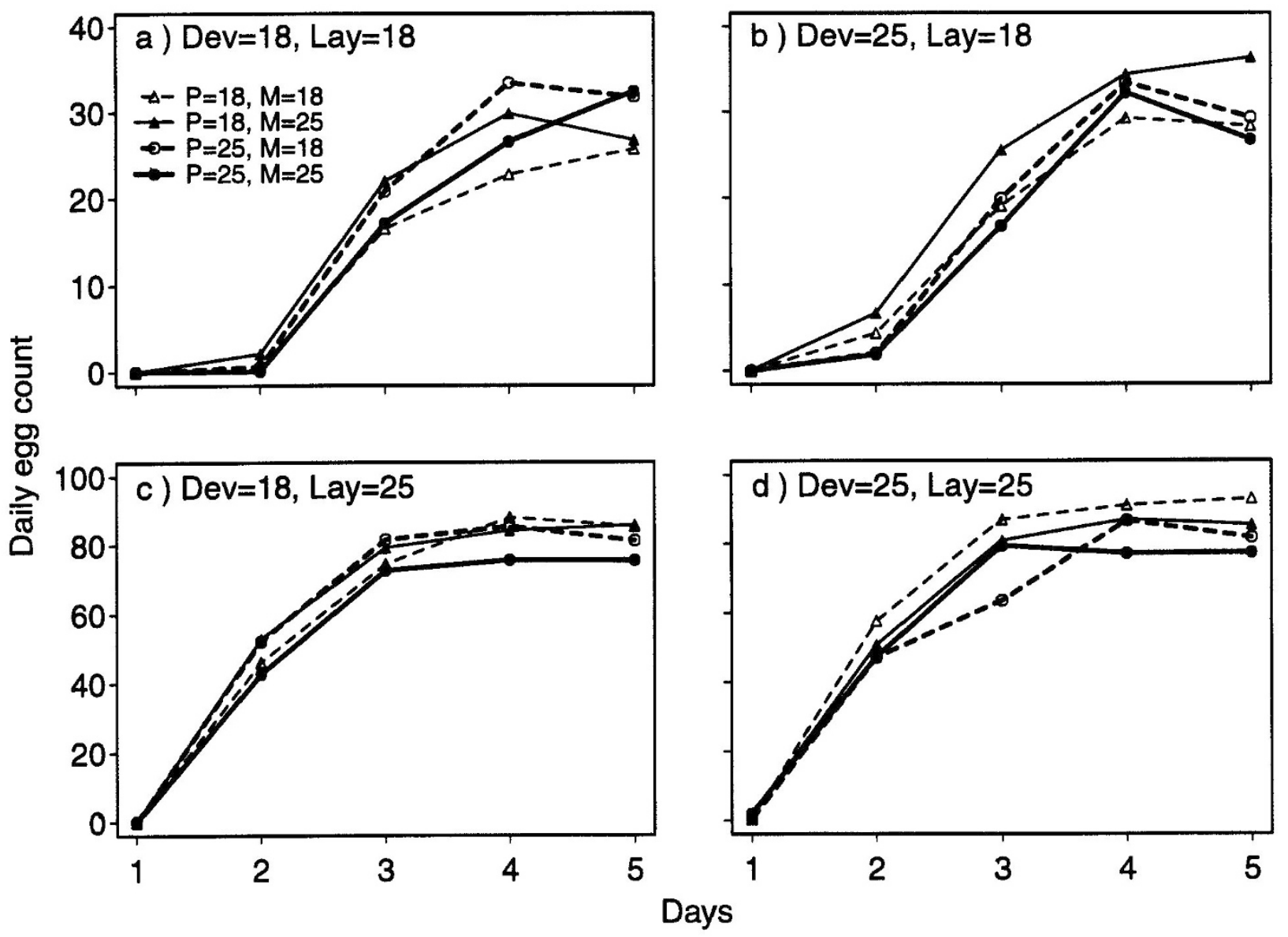

Fig. 1 Daily (mean) egg counts for various temperature treatments of Drosophila melanogaster. Symbols for the four sire-bydam temperature combinations are indicated in (a). Note: the scales of the ordinates differ between the $18^{\circ} \mathrm{C}(\mathrm{a}, \mathrm{b})$ and $25^{\circ} \mathrm{C}(\mathrm{c}$, d) developmental temperature treatments. 
Table 1). Indeed, laying temperature accounted for over 79 per cent of the total variance in a female's fecundity (Table 1, between-subjects analysis, $P \ll 0.001$ ): females laying at $25^{\circ} \mathrm{C}$ produced 3.6 times more eggs over 5 days than did females laying at $18^{\circ} \mathrm{C}$ (Figs 1 and 2).

Two factors contributed to the difference in fecundity between females laying at $25^{\circ} \mathrm{C}$ vs. at $18^{\circ} \mathrm{C}$. Females laying at $25^{\circ} \mathrm{C}$ not only began producing eggs about 1 day earlier, but also laid many more eggs per day than did females laying at $18^{\circ} \mathrm{C}$ (Fig. 1). Thus laying temperature has a strong effect on the pattern of daily egg production (within-subjects analysis, $P<0.001$, Table 2).

\section{Developmental temperature}

Flies that developed at $25^{\circ} \mathrm{C}$ averaged about eight more eggs over 5 days than did flies that developed at $18^{\circ} \mathrm{C}$ (Fig. 2). However, developmental temperature had no significant effect either on overall fecundity (Table $1, P=0.125$ ) or on the pattern of daily egg production (Table $2, P=0.165$ ).

\section{Dam and sire temperature}

Dam temperature did not affect overall fecundity (Table 1, $P=0.617$; Fig. 2). However, dam tempera-

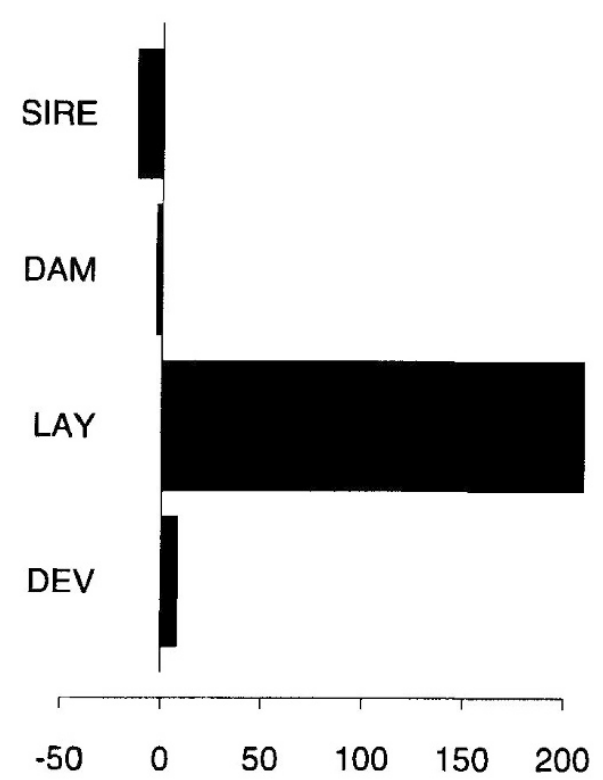

Fig. 2 Summary of the main effects on total fecundity of Drosophila melanogaster during the first 5 days of adult life. Plotted is the difference between the least-squares means for the two temperature levels of each factor, specifically the mean value at $25^{\circ} \mathrm{C}$ minus that at $18^{\circ} \mathrm{C}$. Lay temperature has the largest impact, and flies laying at $25^{\circ} \mathrm{C}$ laid many more eggs than did flies at $18^{\circ} \mathrm{C}$. ture slightly affected the pattern of daily egg production (Table 2, $P=0.021$; Fig. 1).

Sire temperature slightly affected overall fecundity $(P=0.018$, Table 1$)$. However, this effect is very minor relative to that of laying temperature (Fig. 2). Even so, flies whose sire lived at $18^{\circ} \mathrm{C}$ produced on average 7 per cent more eggs than those whose sire lived at $25^{\circ} \mathrm{C}$ (Fig. 2). (Note: a lower sire temperature thus increases his daughter's fecundity, whereas a higher laying temperature increases her fecundity (Fig. 2).) Sire temperature also influenced the pattern of daily egg production $(P=0.050$, Table 2$)$ : females whose sire was raised at $18^{\circ} \mathrm{C}$ tended to lay fewer eggs on day 1 than did females from $25^{\circ} \mathrm{C}$ sires, but the reverse trend is observed during days 2-5 (Fig. 1). However, these effects are very small and are not conspicuous in Fig. 1.

\section{Interactions}

The only significant interaction involving overall fecundity (between-subject analysis, Table 1) involved sire temperature by laying temperature, but this interaction was weak $(P=0.039)$. Three interactions significantly influenced the daily pattern of egg production (within-subjects analysis, Table 2), but all were again weak (all $P>0.01$ ).

\section{Discussion}

\section{General patterns}

Our results demonstrate that laying temperature is by far the dominant factor influencing early fecundity of $D$. melanogaster: indeed, laying temperature alone accounted for 79 per cent of the variance in overall fecundity (Table 1, Fig. 2). Flies laying at $25^{\circ} \mathrm{C}$ not only began producing eggs sooner, but also produced more eggs per day than did flies laying at $18^{\circ} \mathrm{C}$ (Fig. 1). As a consequence, flies laying at $25^{\circ} \mathrm{C}$ produced 3.6 times more eggs over 5 days than did flies laying at $18^{\circ} \mathrm{C}$. The high thermal sensitivity of overall fecundity is reflected in a $\mathrm{Q}_{10}$ of 6.23, which is well above the normal level for physiological processes (2 to 3; Prosser, 1986). (Even for days 4 or 5, the $\mathrm{Q}_{10}$ is still 4.4.) Egg production in Drosophila has, of course, long been known to be very sensitive to laying temperature (TimofeeffRessovsky, 1933; Dobzhansky, 1935; David et al., 1983).

Developmental temperature had no significant effect either on overall fecundity (Fig. 2, Table 1) or on the pattern of daily egg production (Table 2). The effect of developmental temperature on offspring fecundity has previously been studied several times, and any significance of a developmental temperature effect varied depending on the particular developmental tempera- 
tures tested. Kaliss \& Graubard (1936) stated that fecundity was not influenced by developmental temperature $\left(16^{\circ}, 20^{\circ}, 25^{\circ}, 28^{\circ} \mathrm{C}\right)$ in $D$. melanogaster; but their conclusion was based on very small sample sizes and was not accompanied by a statistical analysis. Lints \& Lints (1971) raised hybrids of two highly inbred lines at six temperatures and then maintained all adults at a single temperature $\left(25^{\circ} \mathrm{C}\right)$ : maximum daily fecundity appeared to be similar for intermediate developmental temperatures $\left(19-25^{\circ} \mathrm{C}\right)$ but reduced for more extreme developmental temperatures $\left(16^{\circ}\right.$, $\left.28^{\circ}, 31^{\circ} \mathrm{C}\right)$. McKenzie $(1978)$ raised D. melanogaster at seven temperatures between $12^{\circ} \mathrm{C}$ and $30^{\circ} \mathrm{C}$ and then measured fecundity at $25^{\circ} \mathrm{C}$ over $18 \mathrm{~h}$ (age of flies about 3-4 days): short-term fecundity appeared similar for development between $15^{\circ} \mathrm{C}$ and $25^{\circ} \mathrm{C}$, but dropped markedly for development outside that temperature range $\left(12^{\circ}, 28^{\circ}, 30^{\circ} \mathrm{C}\right)$. In a similar experiment, Cohet \& David (1978) raised D. melanogaster at nine temperatures between $13^{\circ} \mathrm{C}$ and $32^{\circ} \mathrm{C}$ and maintained the adults again at $25^{\circ} \mathrm{C}$ : maximum daily egg production and total egg production appeared maximal for developmental temperatures of $21^{\circ} \mathrm{C}$ and $25^{\circ} \mathrm{C}$, but declined at temperatures outside that range $\left(13^{\circ}, 14^{\circ}\right.$, $17^{\circ}, 28^{\circ}, 30^{\circ}, 31^{\circ}, 32^{\circ} \mathrm{C}$ ).

Overall, these studies suggest that fecundity of $D$. melanogaster is effectively canalized over intermediate developmental temperatures (roughly $16-25^{\circ} \mathrm{C}$ ). This buffering is somewhat surprising, given that females developing at the lower end of this range are much larger in body size than those developing at $25^{\circ} \mathrm{C}$ (e.g. David et al., 1983) and that large females are often relatively fecund (Robertson, 1957).

Fecundity is, however, clearly reduced following development at extreme temperatures (Lints \& Lints, 1971; McKenzie, 1978; Cohet \& David, 1978). Cohet \& David (1978) showed that this reduction reflects either low ovariole number (at high developmental temperature) or a lower rate of oogenesis (at low developmental temperature).

The apparent significant effect of sire's temperature, especially given the absence of a significant effect of dam's temperature, is surprising (Table 1). Maternal effects on insect life-history traits are well established (Mousseau \& Dingle, 1991), but paternal effects have largely been ignored. Interestingly, the photoperiod experienced by a male influences his offspring's metabolic rate (Giesel et al., 1989) and development time (Giesel, 1988); so perhaps paternal effects are more widespread than commonly believed. In any case, the presence of an apparent paternal effect implies that one or more components of a sire's ejaculate (or the sire's behaviour) somehow influence the fecundity of his offspring. Male Drosophila influence the fecundity of their mates (Markow \& Ankney, 1984; Markow, 1988; Partridge et al., 1986; Pitnick, 1991; see also Hoffmann \& Harshman, 1985), and the developmental temperature of a male influences the longevity of its mate (Cohet \& David, 1976). However, to our knowledge, any potential cross-generational effect of a male on the fecundity of his offspring (rather than of his mate) has not previously been documented.

We emphasize that the male and female offspring used in our experiments had the same thermal histories (see Materials and methods). Although this should magnify the possibility of detecting the effect of a given factor (e.g. sire temperature), a much larger-scale experiment will be necessary to determine whether such effects work via the female, her mates or both.

\section{Lack of developmental temperature sensitivity}

Our finding that developmental temperature $\left(18^{\circ} \mathrm{C}\right.$ vs. $25^{\circ} \mathrm{C}$ ) had no significant effect on fecundity early in life contradicts several published hypotheses concerning the developmental sensitivity of fecundity. Firstly, it clearly contradicts a 'body size hypothesis' (Zamudio et al., 1984), which predicts that flies developing at $18^{\circ} \mathrm{C}$ should be relatively fecund because of the large size. If anything, $18^{\circ} \mathrm{C}$ flies are less fecund. Secondly, it contradicts a 'beneficial acclimation hypothesis' (Leroi et al., 1994; Zamudio et al., 1994), which predicts that flies raised at $25^{\circ} \mathrm{C}$ should be more fecund (relative to flies raised at $18^{\circ} \mathrm{C}$ ) if laying at $25^{\circ} \mathrm{C}$, which was the case, but less fecund if laying at $18^{\circ} \mathrm{C}$, which was not. Thirdly, it is inconsistent with the 'optimal developmental temperature hypothesis,' which proposes that flies raised at or near $25^{\circ} \mathrm{C}$ are vigorous (and hence more fecund) than are flies raised at other temperatures (Cohet \& David, 1978; David et al., 1983; Zamudio et al., 1994). Flies raised at $25^{\circ} \mathrm{C}$ did lay about 5 per cent more eggs than those raised at $18^{\circ} \mathrm{C}$ (Fig. 1), but the difference was not significant.

\section{Potential confounding factors}

Our interpretations of the above patterns might be confounded by several issues. Firstly, because we did not determine the proportion of eggs laid that were actually fertilized and viable, our cumulative egg counts could possibily overestimate the number of potential offspring, even ignoring normal mortality between egg and adult. Secondly, natural selection at different temperatures during the experiment might inadvertently have inflated our estimates of phenotypic effects. These two problems are unlikely to have a major impact on our results. In pilot experiments, the viability of eggs was very high and independent of develop- 
mental temperature (see also David \& Clavel, 1967; McKenzie, 1978). Moreover, given that the heritability of fecundity is generally low (see table 1 in Roff \& Mousseau, 1987), any selection during this experiment should have minimal effects.

Our results apply only to the impact of various epigenetic factors on fecundity over the first few days of life (see Introduction). Nevertheless, this restricted time period is ecologically relevant, given the very short life spans of Drosophila in nature (Rosewell \& Shorrocks, 1987), at least in warm seasons. Even so, the patterns we detected might well hold for lifetime fecundity. Life span is sensitive to developmental temperature (Lints \& Lints, 1971; Cohet \& David, 1978; Zwaan et al., 1992); however, the duration of the laying phase is remarkably independent of developmental temperature between $14^{\circ}$ and $28^{\circ} \mathrm{C}$ (Cohet \& David, 1978).

\section{Final remarks}

Our study emphasizes that early fecundity, which represents a key component of fitness (Stearns \& Kawecki, 1995), is particularly sensitive to the immediate thermal environment of the adult fly, and much less so to that of its parents or of its own development. This sensitivity to laying temperature does not necessarily imply, however, that the fecundity of flies in nature will vary greatly with weather conditions or with climate. Adult flies are mobile and often will have ample opportunities to thermoregulate behaviourally (Jones et al., 1987). Behaviour may thus serve as an effective buffer against sensitivity to environmental temperatures.

\section{Acknowledgements}

We thank L. Harshman and M. Turelli for providing the flies we studied; D. Berrigan, J. David, J. Felsenstein, A. Hoffmann, J. Kingsolver, T. Markow, L. Partridge, S. Stearns and J. Truman for very constructive discussion; A. Hoffmann for statistical advice; and also P. Sampson and the Statistical Consulting Service of the Department of Statistics, University of Washington for statistical advice. Financial support was provided by the College of Arts and Sciences (University of Washington) and by National Science Foundation grant DEB-9301151 to RBH and the Howard Hughes Foundation to TW.

\section{References}

ASHBURner, m. 1989. Drosophila. A Laboratory Handbook. Cold Spring Harbor Laboratories, Cold Spring Harbor, New York.
COHET, Y. AND DAVID, J. 1976. Deleterious effects of copulation in Drosophila females as a function of growth temperature of both sexes. Experientia, 32, 696-697.

COHET, Y. AND DAVID, J. 1978. Control of adult reproductive potential by preimaginal thermal conditions. Oecologia (Berlin), 36, 295-306.

DAAN, S., DIJKSTRA, C. AND TINBERGEN, J. M. 1990 . Family planning in the kestrel (Falco tinnunculus): the ultimate control of covariation of laying data and clutch size. Behaviour, 114, 83-116.

DAVID, J. R. 1988. Temperature. In: Lints, F. A. and Soliman, M. H. (eds) Drosophila as a Model Organism for Ageing Studies, pp. 35-45. Blackie, Glasgow.

DAVID, J. R., ALLEMAND, R., VAN HERREWEGE, J. AND COHET, Y. 1983. Ecophysiology: abiotic factors. In: Ashburner, M., Carson, H. L. and Thompson, J. N. (eds) The Genetics and Biology of Drosophila, vol. 3d, pp. 106-169. Academic Press, London.

DAVID, J. R. AND CLAVEL, M.-F. 1967. Influence de la température d'élevage sur la mortalité larvo-nymphale et la durée de développement de la Drosophile. Naturaliste Can., 94, 209-219.

DOBZHANSKY, т. 1935. Fecundity in Drosophila pseudoobscura at different temperatures. J. Exp. Zool., 71, 449-464.

GIESEL, J. T. 1988. Effects of parental photoperiod on development time and density sensitivity of progeny of Drosophila melanogaster. Evolution, 42, 1348-1350.

GIESEL, J. T., LANCIANI, C. A. AND ANDERSON, J. F. 1989. Effects of parental photoperiod on metabolic rate in Drosophila melanogaster. Florida Entomol., 71, 499-503.

HOFFMANN, A. A. AND HARSHMAN, L. G. 1985. Male effects on fecundity in Drosophila melanogaster. Evolution, 39, 638-644.

IZQUIERDO, J. L. 1991. How does Drosophila melanogaster overwinter? Entomologia exp. appl., 59, 51-58.

JONES, J. S., COYNE, J. A. AND PARTRIDGE, L. 1987. Estimation of the thermal niche of Drosophila melanogaster using a temperature-senstive mutant. Am. Nat., 130, 83-90.

KALISs, N. AND GRAUBARD, M. A. 1936. The effect of temperature on oviposition in Drosophila melanogaster. Biol. Bull. (Woods Hole), 70, 385-391.

KIRKPATRICK, M. AND LANDE. R. 1989. The evolution of maternal characters. Evolution, 43, 485-503.

KOHANE, M. J. AND PARSONS, P. A. 1986. Environment-dependent fitness differences in Drosophila melanogaster: temperature, domestication and the alcohol dehydrogenase locus. Heredity, 57, 289-304.

LEROI, A. M., BENNETT, A. F. AND LENSKI, R. E. 1994. Temperature acclimation and competitive fitness: an experimental test of the Beneficial Acclimation Assumption. Proc. Natl. Acad. Sci. U.S.A., 91, 1917-1921.

LINTS, F. A. AND LINTS, C. v. 1971. Influence of preimaginal environment on fecundity and ageing in Drosophila melanogaster hybrids. II. Preimaginal temperature. Exp. Geront., 6, 417-426.

LONG, C. E., MARKOW, T. A. AND YAEGER, P. 1980. Relative male age, fertility, and competitive mating success in Drosophila melanogaster. Behav. Genet., 10, 163-170. 
McKENZIE, J. A. 1975. The influence of low temperature on survival and reproduction in populations of Drosophila melanogaster. Aust. J. Zool., 23, 237-247.

McKENZIE, J. A. 1978. The effect of developmental temperature on population flexibility in Drosophila melanogaster and D. simulans. Aust. J. Zool., 26, 105-112.

MARKow, T. A. 1988. Drosophila males provide a material contribution to oogenesis in a multiple mating species. Funct. Ecol., 2, 77-79.

MARKow, T. A. AND ANKNEY, P. F. 1984. Drosophila males contribute to oogenesis in a multiple mating species. Science, 224, 302-303.

MOUSSEAU, T. A. AND DINGLE, H. 1991. Maternal effects in insect life histories. Ann. Rev. Entomol., 36, 511-534.

PARSONS, P. A. 1978. Boundary conditions for Drosophila resource utilization in temperature regions, especially at low temperatures. Am. Nat., 112, 1063-1074.

PARTRIDGE, L., FOWLER, K., TREVITT, S. AND SHARP, w. 1986. An examination of the effects of males on the survival and egg-production rates of female Drosophila melanogaster. J. Insect Physiol., 32, 925-929.

PITNICK, s. 1991. Male size influences mate fecundity and remating interval in Drosophila melanogaster. Anim. Behav., 41, 735-745.

PRosser, C. L. 1986. Adaptational Biology: Molecules to Organisms. John Wiley \& Sons, New York.

RISKA, B., PROUT, T. AND TURELLI, M. 1989. Laboratory estimates of heritabilities and genetic correlations in nature. Genetics, 123, 865-871.

RISKA, B., RUTLEDGE, J. J. AND ATCHLEY, W. R. 1985. Covariance between direct and maternal effects in mice, with a model of persistent environmental influences. Genet. Res., 45, 287-297.

ROBERTSON, F. W. 1957. Studies in quantitative inheritance. XI. Genetic and environmental correlation between body size and egg production in Drosophila melanogaster. J. Genet., 55, 428-443.
ROBERTSON, F. W. AND SANG, J. H. 1944. The ecological determinants of population growth in a Drosophila culture. I. Fecundity of adult flies. Proc. R. Soc. B, 132, 258-289.

RoFf, D. A. 1992. The Evolution of Life Histories. Chapman \& Hall, New York.

ROFF, D. A. AND MOUSSEAU, T. A. 1987. Quantitative genetics and fitness: lessons from Drosophila. Heredity, 58, 103-118.

ROSEWELL, J. AND SHORROCKS, B. 1987. The implication of survival rates in natural populations of Drosophila: capture-recapture experiments on domestic species. Biol. J. Linn. Soc., 32, 373-384.

SANG, J. H. 1950. Population growth in Drosophila cultures. Biol. Rev. Camb. Phil. Soc., 25, 188-239.

SERVICE, P. M. AND ROSE, M. R. 1985. Genetic covariations among life-history components: the effect of novel environments. Evolution, 39, 943-945.

STEARnS, s. c. 1992. The Evolution of Life Histories. Oxford University Press, Oxford.

STEARNS, S. C. AND KAWECKI, T. J. 1995. Fitness sensitivity and the canalization of life history traits. Evolution (in press).

TAYLOR, F. 1981. Ecology and evolution of physiological time in insects. Am. Nat., 117, 1-23.

TIMOFEEFF-RESSOVSKY, N. w. 1933. Über die relative Vitalität von Drosophila melanogaster Meigen und Drosophila funebris Fabricius (Diptera, Muscidae acalypteratae) unter verschiedenen Zuchtbedingungen, in Zusammenhang mit den Verbreitungsarealen dieser Arten. Arch. Naturgesch., N.F., 2, 285-290.

ZAMUDIO, K. R., HUEY, R. B. AND CRILL, W. D. 1994. Bigger isn't always better: body size, developmental and parental temperature, and male territorial success in Drosophila melanogaster. Anim. Behav. (in press).

ZWAAN, B. J., BIJLSMA, R. AND HOEKSTRA, R. F. 1992. On the developmental theory of ageing. II. The effect of developmental temperature on longevity in relation to adult body size in D. melanogaster. Heredity, 68, 123-130. 